\title{
EARLY CONVERSATIONS: COMMUNICATION AND DIALOGUE ${ }^{1}$ CONVERSACIONES TEMPRANAS: COMUNICACIÓN Y DIÁLOGO
}

\author{
VASUdEVI REDDY \\ University of Portsmouth. Portsmouth. UK \\ Vasu.Reddy@port.ac.uk
}

\begin{abstract}
What is dialogue and how can we find it? This paper addresses this question in the context of tracing the origins of communication in human infancy. Structural criteria - such as turn taking - have often been used to identify genuine communication. Implementing these criteria have led to considerable debate in relation to the 'proto-conversations' of the twomonth-old, debates which arose in the late 1970s and are still alive today. The paper considers some of the evidence from infant behaviour involved in these debates and in relation to the question of infants' awareness of the 'meaning' of adult facial expressions. In addition to these structural criteria it is suggested that functional criteria such as openness and recognition might be important for our understanding of the origins of dialogue. The paper discusses the apparent paradox of language how communication is needed to make private experience public, but at the same time, cannot occur until experience is already public - and argues that this paradox disappears if shared experience rather than private representation is taken as primary.
\end{abstract}

Key Words

Communication, dialogue, intersubjectivity, infancy, proto-conversation.

"Of all affairs" said the great educationalist and philosopher John Dewey (1925), "communication is the most wonderful". Communication and dialogue creates and transforms the individual and the realm of meanings, but also, intriguingly, seems to demonstrate the recognition of another being. You would not have a dialogue with someone unless you took for granted, or at least hoped, that they were minded beings, capable - at some level - of understanding and responding. Unless you are Shirley Valentine talking to her wall or John Cleese talking to his Mini, talk seriously to a mindless thing and you run the risk of being labelled mad. So if we generally reserve dialogue and communication for creatures with minds, they must imply a prior recognition of mentality. But what makes an exchange a dialogue? Can we have dialogue without content - can we have conversations about nothing? In this work I will look at the proto-conversations of the two-

Artículo recibido: 12/4/2010

Artículo aceptado: 20/5/2010

${ }^{1}$ An extended version of this work was published as a chapter in the book How infants know minds, Harvard University Press, 2008. 
month-old - the face-to-face 'chatting' with neither words nor topic - a phenomenon which is still controversial after many years of debate and still central to claims about the early origins of intersubjectivity. I will start first, though, with the question 'what is dialogue?'

\section{What is dialogue?}

How would you answer this question? Perhaps you might say that to be considered dialogue, each partner in an interaction must have at least some recognition of the consciousness of the other, some kind of openness to the acts of the other and show some taking of turns in responding to the other's acts. The answer may seem obvious, but it is far from agreed upon. And it is no mere academic debate: doubts about the meaning or relevance of dialogue influence how we act and even parents in their everyday interactions can be stricken with doubt about whether some early exchanges are really communicative (although such doubts, do not, fortunately, stop most parents from continuing to chat with their infants). Most of developmental psychology was and still is sceptical about the possibility of genuine communication before the end of the first year. In trying to pin down communication, psychology generally focuses on language and the communication of 'information', of meanings about things outside both partners. Simple exchanges of smiles and vocalisations are seen as meaning-less in this sense, and often, as somehow biologically driven and less than intentional.

In the sceptical atmosphere of the late 1960s and early 1970s, Mary Catherine Bateson, (inspired by a film of a 9-week-old infant with mother which she reportedly saw while she herself was pregnant) was the first to call the interactions of two month-olds 'proto-conversations'. There was a strange zeitgeist in the air and the work of several independent researchers (Berry Brazelton, Jerome Bruner, Hanus Papousek, Daniel Stern and Colwyn Trevarthen) began to converge on the early communicative abilities of very young infants (see Trevarthen, 1998). Within a few years infant communicative skills hit the headlines and debates were raging. Trevarthen's claim that not only were these very young infants having 'conversations', but that they involved an 'innate intersubjectivity' or the ability to share and participate in another person's feelings and thoughts, was a serious challenge to mainstream views.

These early 'communications' were dismissed by some as 'pseudo- (rather than proto) conversations' (just as Piaget and others had previously used the term 'pseudo-imitation'). The dismissals were motivated by cautions and a priori theoretical convictions that came from a variety of traditions. The behaviourist - Social Learning Theory - tradition objected because they sought to explain the interactions as the result of a variety of learned associations and reinforcements. The newer cognitivist - or at least Piagetian - tradition objected both because their idea of interpersonal understanding began with a profound childhood egocentrism and because they were beginning to require elaborate evidence of mental representational skill for countenancing any claims communication. Needless to say, the now familiar dualism of mind and behaviour underpinned both these objections. Where communication was defined as a 'mindto-mind' process, infants of that age were seen as simply too young to be able to grasp the idea of minds in order to communicate with them. Where the emphasis was on a more behavioural construct of interacting reinforcements and contingencies, the behaviour of the infants (and indeed the adults) was seen as resulting from environmental and other behavioural constraints with no need to invoke the fancy mentalistic labels of intersubjectivity and communication.

The strongest caution, however, came from a new tradition - social constructionism - which resisted the individualism of Piaget and embraced a deep sociality from the traditions of George Herbert Mead and Lev Vygotsky. The Norwegian philosopher Ragnar Rommetveit wrote in 1974 that "intersubjectivity has to be taken for granted in order to be achieved" and this, now famous, dictum was applied to infancy to mean that it is only if mothers act 'as-if' their infants could understand them that the infants actually come to understand them. Intersubjectivity was seen to emerge in relation, but with an interesting twist: through a mistaken attribution by one or both of the partners in the relation (in this case by the mother) about the intentions and understanding of the other. Within this camp the theo- 
rist could remain agnostic about what the infants in fact 'understood' about the other person, or about what the infants' actions actually 'meant' before the attributions were made.

However, Rommetveit's dictum can be interpreted another way: that in order to initiate any interpersonal communication the initiator must presuppose intersubjectivity (Markova, 1982). That is, that the infant's initiation of communication is evidence of the infant's recognition of another's subjectivity. Of course, not only is defining what constitutes communication a controversial issue, but even defining initiation is problematic our communications are deeply embedded in each others' reactions - who is to say where an individual stops responding and starts initiating?

Nonetheless, this slant takes emphasis away from social constructionism and maternal selffulfilling beliefs and attributions and instead puts the onus on our descriptions of what infants do as well - do they in fact initiate interpersonal communication? In the literature on animal communication there is considerable evidence of young mammals calling for attention and company; in babies, however, although there is a large literature on crying, there is a strange neglect of positive calling (although see Legerstee, 1994). Mothers report that by about two or three months of age, there is a 'calling' tone in infant vocalisations, used when they are not being attended to and very different from a responsive tone used when engagement is already established; precisely what the infant is calling the other for remains to be established: for face-to-face attention, for physical contact, for vocal exchanges, for entertainment. Vocal initiations by infants within engagement, however, are commonplace, often picked up by parents and imitated.

It is clear that in order to unpick this quagmire we need to have a good look at what conversations with two-month-olds are actually like. But how do we do this?

\section{Structural features of dialogue and communication}

One way of deciding whether an interaction really is communication might be to look to the structural features generally identified as occurring in conversations between human adults (with the caution that using the criteria of a more mature version of the phenomenon carries the risk of obscuring from our view the very origins we seek). Such features include a repertoire of communicative acts (such as expressions, words, gestures), self-synchrony (the ability to produce organised and coherent actions), interactional and affective synchrony (the ability to relate your own actions and emotions to the other's actions and emotions), turn-taking (an ability to take turns in acts), attentional co-ordination (i.e., the ability to know when someone is attending to you and to co-ordinate your attention with the other's to a third thing), reference (i.e., the ability to point or verbally refer to things), information content (i.e., the ability to say something about these things), symbolism (i.e., the ability to use arbitrary symbols to stand for things), grammatical and textual competence (i.e., the ability to produce and comprehend well-formed sentences and to link sentences together to convey large amounts of information) and socio-linguistic competence (i.e., the ability to discriminate between the rules and needs of different situations and audiences). Over the course of the first year infant communication develops to show at least some competence in most of these features. How does communication begin?

Trevarthen and his student, the late Penny Hubley, conducted a classic study of a baby called Tracy, following her monthly from the first month through to the end of the first year. They found several distinctive changes in her interests and her 'communicative' actions with her mother over the course of the first year: most notable among these were the onset of intense face to face chatting at around two months, shifting to a marked interest in the environment at three to four months, leading to a period of games in the middle of the first year as the mother, fed up with the infant's wandering attention, used rhythmic games and songs to keep the baby chatting, and finally, from about 9 months to the onset of a triadic interaction between mother, baby and the objects around them. Trevarthen distinguished between the nature of communication at two months which he called primary intersubjectivity, and that at 9 to 
12 months, which he called secondary intersubjectivity. These labels and the engagements they refer to have now become part of the furniture for students of developmental psychology. But the interpretation of the exchanges at two months is still hotly debated by theorists.

It is the first four features in the list above which Trevarthen highlights as particularly significant for his argument that the smiling, cooing and 'chatting' of the two-month-old are conversational and intentionally communicative. First, these actions are in themselves significant as precursors of adult speech movements, involving lip movements and movements of the tongue inside the mouth during and prior to vocalisations he called 'pre-speech' movements, that is, movements of the appropriate organs even before speech. These occur in co-ordination with smiles, vocalisations, and arm movements. In other words, two-month-old infants are using communicative behaviours which we as adults recognise as such. Second, they are coherent. That is, these behaviours are not random emissions but co-occur in organised patterns. In the same way that when we turn to talk to someone we may look, smile, adjust our bodies and say something all at the same time, the two-month-old infant's smiles, vocalisations and arm movements also occur together in a pattern. Various body parts are involved in vocal conversation, each often moving in different directions and at different velocities but maintaining a relationship with one another and constituting a 'movement bundle', revealing what some have called 'self-synchrony'. Third, the infant behaviours occur in conversational turns, with first one partner and then the other, 'saying' something, rather than in a chaotic overlap. Many studies have found a minimal overlap of vocalisations between infant and mother. Fourth, they express emotions which are reciprocally related to the emotions of others, implying some kind of recognition of what others' emotional expressions mean. While the first two features (the presence and coherence of 'communicative' behaviours) are unchallenged, the last two are controversial, and provide the key both to understanding how infant communication begins and develops and to how communication relates to the awareness of other minds.

\section{Turn-taking and engagement}

One criticism of turn-taking comes from Kenneth Kaye who argued that much as Fred Astaire famously danced the tango with a hat stand, mothers in fact create an illusion of interco-ordination. During early feeding interactions mothers tend to jiggle their babies between their bursts of sucking, an alternation that looks very much like a coordinated dialogue. Mothers believe that the jiggling helps to provoke the baby to start sucking again. In fact, he says, the jiggling has remarkably little effect on the infant. It serves simply to give the mother the illusion of a conversation and to set the pattern of turns for the future. In the same way, he argues, it could be that the turn-taking pattern of conversations with two-month-olds is created by the mothers slotting their responses into the gaps between the infant's acts, rather than by the infant actively waiting for its turn. The effect could be a 'pseudo-dialogue' in which the infant simply does her bit, regardless of what the mother does. That is, the coordination could be merely apparent, with the infant's actions not 'responses' to, or dependent on, the mother's. Indeed some argued that you could in fact impose this gloss on the exchanges between two month-olds and their mothers (Kaye, 1982). While the mother's acts may not really matter to the infant, the mother could be taking note of the infant's utterances and acts, and by unconscious use of the gaps, creating the illusion that the infants are responding in coherent turns. Such an illusion could be really useful - helping to shape the mother's interactive behaviour to the infant and promote the infant's development - but ultimately it would be an illusion.

Is such turn-taking really illusory? Are the infant's responses not responses at all, but independent acts? It was to answer this sort of question that three separate labs (Colwyn Trevarthen's, Hanus and Mechthilde Papousek's and Ed Tronick's) developed what have become known as perturbation experiments. Lynne Murray, then a doctoral student of Trevarthen's, developed what she called the 'blank face test' (Trevartehn, 1977), a test which Ed Tronick, independently and famously developed as the 'still face experiments' (Tronick, Als, Adamson, Wise \& Brazelton, 1978). In these experiments, all you 
have to do is to get a 'conversation' going with a baby and in the middle of it just hold your face still in a pleasant expression, continuing to look at the baby but not talking or responding in any way. If your responses don't really matter, the baby should carry on 'emitting' her acts regardless. But they do matter, sometimes dramatically so (Reddy \& Trevarthen, 2004).

Many versions of the still face study have now been published - and distress in the infants to the unresponsiveness of a partner has been demonstrated time and again (see reviews by Tronick, 2003; Adamson \& Frick 2003; Mesman, van Ijzendoorn \& Bakermans-Kranenburg, 2009). The infants' negative reaction is worse when the still-faced person is their mother someone they are familiar with - and worse when the person holds the still-face while looking at them. The infants seem to have strong and 'sensible' expectancies for the other person's actions in relation to them: the mother's inaction evidently affects the infant's responses. The responses of infants whose mothers have postpartum depression, however, show little difference from 'normal' conversational conditions, suggesting that their experiences may not have established these stable expectations.

There is other evidence that early conversations involve genuine turn-taking: Ed Tronick and his colleagues showed that even in structural terms the interaction at two months is appropriately describable as a conversation. The mother emits a large number of what are called turn-yielding signals common to adult conversation (such as changing intonation, drawling, moving the head, and occasionally the hands, at the end of a 'turn') and the infant modifies her behaviour in relation to these signals, particularly in relation to intonation changes, starting at such points to smile and vocalise more. The infant is not an equal partner in the dialogue, but does take turns and does participate actively in it. Simultaneous (or co-active and overlapping) vocalisations between infant and mother also occur, as Daniel Stern showed, but they appear to occur more during high arousal times such as during active play, when both may laugh or squeal together. The co-occurrence of such vocalisations, or of non-vocal facial and gestural expressions, does not seriously limit the ability to take in what the other is doing at the same time. It is only later when the linguistic content of the vocal utterances becomes important that it is necessary for the infant (or adult) to wait in complete silence while another makes an utterance. Although, it is certainly the case that adults don't always wait during conversations, as anybody who has tried to transcribe a tape of a conversation has painfully discovered. Still, conversations are held and understood.

The answers from these studies showed clearly that a lack of response is noticed by and matters to the two-month-old. Infants show signs of attempting to regain the mother's engagement, as well as signs of distress when they fail to do so. However, what does this mean? It could be that the infant simply finds the rather odd behaviour of the mother - different from what she has been used to - upsetting. It could be the difference rather than the unresponsiveness per se that the infant dislikes. To explore this question, Lynne Murray, influenced by a visit to the Papouseks' laboratory in Munich in 1975, devised with Trevarthen an ingenious experiment involving closed circuit television. They got two-month-olds to interact with their mothers through television monitors. That is, the baby was looking into a monitor in which his/her mother's face could be seen, live, and the mother was, similiarly, looking into a monitor that framed her infant's face. The two partners were then encouraged to interact as usual; despite the strangeness of this technological mediation, it was clear (judging by the vocalisations and facial expressions of both) that perfectly happy interactions could occur between mothers and infants. Importantly for the procedure, the behaviour that each partner displayed during these live interactions could be surreptitiously video-taped. So, once happy interaction had been established (and taped) for a while, the video-tape would be surreptitiously rewound, and unbeknown to both infant and mother, replayed to them. Instead of seeing the mother live, the infant would now view the mother as she had been a few minutes earlier. The results showed that infants reacted in much the same way as they did during the paradigm of the still face. That is, they showed fewer smiles, looked away, exhibited more closed mouth expressions, and intermittently attempted to regain interaction. In short, they could de- 
tect the changes in the mother's behaviour. Even when the mother was smiling and chatting - the very same smiles and conversational offerings from the mother that had a minute previously produced happy responses in the infant the infant looked sober and wary.

Clearly it was not just odd behaviour by the mother which was disliked by the infant. A few minutes earlier, the infants had responded happily to the very same behaviour. The problem seemed to be the inappropriateness of the responses, the fact that the mother's behaviour was not a response to what the infant did. Interestingly, the mothers - who were unaware of what was happening - also reacted with puzzlement to their babies' behaviour. They could still see the baby live, but did not know that the baby was no longer viewing a live image of the mothers themselves. The mothers could detect, however, that the babies were no longer engaged with them and that they were behaving oddly and unresponsively. The mothers thus also became less engaged, starting to speak and interact with less 'motherese' (the typical higher pitched and exaggerated utterances most adults unthinkingly use when speaking to babies). The specific responses of the two-month-old seemed to matter to the adult as much as the specific responses of the adult mattered to the infant (Murray, 1980; Murray \& Trevarthen, 1985; Nadel et al. 1999)

Instances of mis-communication are not limited to experimental manipulations. As Ed Tronick and his colleagues have shown, they happen all the time in normal interaction, with periods of mis-coordination and repair (getting in tune again) alternating every few seconds. When infants chronically experience prolonged mis-coordinated interactions without the experience of the repair, that they seem to regularly withdraw from the other person, showing behaviour such as turning away, having dull looking eyes, poor postural control, much oral selfcomforting (e.g., fingers in the mouth), rocking and self-clasping. This is also the sort of reaction that has been noted in many studies of post-natal depression or in situations of neglect. Interestingly, such infants show more looking away during still-face experiments than do infants who have had more normal experience of repair of interactions. Other studies have shown that lack of experience of interactive repairs seems to lead to later problems in elaborating communicative skills and problems in the establishment of a positive 'affective core' and a sense of effectiveness. These studies show us very slightly exaggerated versions of what the infant normally experiences, and show us how much mis-communication does matter in everyday life if failure to repair it becomes chronic (Tronick, 1989; Gianino \& Tronick, 1988).

\section{Reciprocal communication of affects}

So, the infant's interactions with adults at two months show clear evidence of engagement, with some evidence of turn-taking by infants. The claim that they are merely pseudo-conversations does not stand up. But what does this engagement actually say about the infant's knowledge of the $(\mathrm{m})$ other's mind? According to the Hungarian Gyorgy Gergely, a very recent critic of the intersubjectivity argument, the infant is equipped with a capacity for contingency detection which says nothing at all about intersubjectivity or mind knowledge. That is, just because the infant can respond in a timely fashion to mother's actions, or detect the untimeliness of hers, does not mean that the infant is engaging psychologically - communicating - with the other. Gergely argues that this capacity i.e., the infant's ability to detect the close temporal sequencing of events such as 'I gurgle mother smiles' - allows infants (like adults) to feel causally effective (or 'empowered' to use adult jargon) and therefore positively aroused. Combined with some predispositions to engage in affective displays and interactions (the motivation for which is inexplicable unless conceived of as 'hard-wired' action patterns), contingency detection alone, he argues, is sufficient to explain the interactive behaviour of the twomonth-old. Primary intersubjectivity, according to him, is a myth. Building on John Watson's theory about the effects of experiencing different kinds of contingencies, Gergely further links contingency detection to the subsequent formation by the child of theories of mind (Gergely, 2003; 2004; Gergely \& Watson, 1996).

This theory has clear assumptions. Attributing physical-temporal contingency detection to 
the infant is seen as acceptable, while attributing emotional-psychological feature detection is not. Attributing a rudimentary understanding of the causality of physical events is seen as acceptable while attributing a rudimentary understanding of the psychological meaning of acts is not. The distinction here is that physical things can be perceived and understood by babies, but mental things cannot be perceived and can therefore only be inferred and theorised - a clear mind-behaviour dualism. However, the problem with dualisms aside, is it the case that very young infants detect only the temporal relations of interpersonal acts and not their emotional relations or relevance?

To answer this question we need to look in detail at the content of the engagement, not simply at its contingent nature. Trevarthen argues that what the two-month-old is doing is engaging in a communication of emotions. She is revealing her emotional state and is perceiving the emotional state of her partner as it relates to her. The emotional tone expressed by each partner is not identical, but reciprocal. That is, some emotional states are most appropriately responded to with the same emotion - such as joy and pleasure - but others are most appropriately responded to with a different emotional tone. Anger for instance could more appropriately evoke a response of distress or even fear, forcefulness could evoke a response of withdrawal and reticence a response of boldness. Ed Tronick's 'mutual regulation model' argues that infants at two months are not only engaging in just such a reciprocal affective interaction, but trying to influence and maintain the partner's affective state.

The evidence for infant responses to emotional expressions and emotional tone in others is still sparse and somewhat contradictory. On the one hand there is evidence to show that even newborns (at 36 hours after birth) discriminate between the posed expressions of happiness, sadness and surprise, responding to each with different but appropriate imitative actions although infants of mothers who were depressed seemed to show less expressiveness to surprise and happy expressions (Field, Woodson, Greenberg \& Cohen, 1982; Lindy \& Field, 1996). Newborns respond to distress vocalisations of other infants (but not their own), played via audio equipment, with facial signs of distress and a reduction in non-nutritive sucking (Dondi, Simion \& Coltran, 1999). Two montholds (but interestingly not five month-olds) can discriminate happy from neutral expressions posed in a holographic image (Nelson \& Horowitz, 1983). Young infants also seem to prefer to look more at certain facial expressions (such as joy) than at others (such as anger) (Izard \& Malatesta, 1987). Different kinds of maternal expressions have a different impact on the infant: gentle friendly approaches often lead to smiles and increased interest, while vocal and facial displays of anger lead to upset or fearful responses and displays of sadness lead to selfsoothing (increased 'tongueing') behaviour even in 10 week old infants (Haviland \& Lelwica, 1987). These infant emotional responses do not show a passive mirroring of whatever the adult experiences, rather they seem to show some appreciation of the other's expression in context and a response to it. Three month-olds whose mothers report more anger during an interaction themselves express more anger, but three month-olds whose mothers reported more sadness express more distress (Hamilton, 1990). In short, the two-month-old appears to be sensitive to micro-emotional shifts in others' expressions within engagement: when maternal mood shifts downward from the positive to the slightly negative, infants in the seconds following can show a rapid decrease in 'brightness' and shift in attention (Hatzinikolaou, 2002).

On the other hand, there is evidence suggesting that although it is easy to show discrimination in three month-olds between different expressions of the same person in photographs, this discrimination does not clearly generalise across different faces or to different orientations of faces (for instance, upside-down faces). This has led to the conclusion that what is being discriminated may not be the expressions per se, but some features of their occurrence in the ongoing context. That is, it may be that the twomonth-old infant does not have a categorical awareness - a concept - of particular emotional expressions, and that not until after six or seven months of age is there consistent evidence that the infant not only treats facial expressions as examples of a general category, but also seems to link them meaningfully to things in the out- 
side world. The meaning of emotional expressions for the two-month-old seems to be an interactive meaning rather than an abstracted one. That an interactive meaning is present is shown clearly by infant responses to affect in actual engagement, both when affect is experimentally simulated and when it is real (see also Adamson, 1995).

Trying to distinguish between mere contingencies and affective responsiveness, Maria Legerstee from Toronto measured the extent of affective mirroring that different mothers showed in live interaction. Still using the double video paradigm, and dividing mothers into high affect mirroring and low affect mirroring groups, she found that the three-month-old babies of both groups of mothers were able to detect the contingency violation of the replay condition and respond to it with greater averted gaze. However, the babies of the high affect mirroring group not only showed greater smiling, gaze and melodic vocalisations in the live interactions, but showed greater negative reactions during the replay, although in the group where the replay was shown first, they did recover their interest during the live condition, unlike the babies of the low affect mirroring group. This complex study raises as many further questions as it addresses. It suggests, however, that affective engagement between infants and mothers is a reality which sets infants up for greater negativeness when the engagement is disrupted but also greater confidence in accepting it when it returns (Legerstee \& Varghese, 2001). Moreover, even the 5-week-old babies of highly affectively attuned mothers discriminate between normal engagement (with intermittent rather than perfectly matching contingencies) and imitative (closely contingent) or non-contingent displays by the mother, while the babies of les affectively attuned mothers don't (Markova \& Legerstee, 2006). The direction of influence in this study seems to be from affective response to contingency rather than the other way round!

Maternal depression provides a difficult situation where infants experience prolonged exposure to a partner who is not always contingently responsive and shows flattened affect, more facial and vocal sadness, often more anger and less joyfulness. Infants are rapidly affected by such interactions, themselves picking up the af- fective patterns and showing them even when interacting with other people. Interestingly even the brief simulation of depression by the mother (interacting in an emotionally flat and withdrawn manner) has a negative impact on the infant's ability to engage with others, leading to more flatness of affect and withdrawal in the infant (Cohn \& Tronick, 1983). Tiffany Field suggests that these infants may learn 'helplessness' and have an impaired sense of control in their engagements - a theory which can explain Legerstee's findings. However, there is room for optimism: these effects can be alleviated with appropriate interventions. Field reports the reassuring results of an intervention programme in which mothers with depression were trained in simple ways to respond contingently to their infants, to imitate them and show more positive affect. Infants and mothers improved in their communication with each other and with others. Are the infants of depressed mothers learning 'how to be' from the mother as a model? Is the mother providing a sort of 'maternal prototype'? Recent suggestions that later in the first year the babies of depressed mothers may in fact be more active - in terms of gaze and movements - than the babies of 'normal' mothers suggests that the situation may be more complex, at least in the second half of the first year (Selby \& Bradley, 2003). A responsive - or compensatory - model of the engagement of affects seems more appropriate than a modelling one. This implies something like a dialogic process.

The idea that the two-month-old detects only temporal contingencies and not the emotional relations or relevance of interpersonal acts therefore cannot be upheld. In attempting to reject the overly nativist heritage of infant communication research, Gergely's rejection of the two month old as communicator seems to adopt the trappings of the very Cartesian model it is opposed to. It clings to a mind-behaviour dualism by distinguishing the physical features that infants can supposedly detect from the psychological features they supposedly cannot and by disallowing the infant from meaningful perception of emotion. Gergely argues that the dispositional meanings of emotion are gained by the infant simply from observation of the action consequences of the emotion displays produced by others (Gergely, 2004). This is a fundamen- 
tally third person theory - the observer deduces all, even the feeling of emotions. There is no room here for emotional responses in the infant as constituting either the dispositional meanings of the observed displays or indeed even as influencing the emotional displays themselves. Ed Tronick uses a notion called dyadic expansion to capture the way in which the infant's experiences can expand in complexity within a dyadic base: dyadic engagement stretches the infant a step beyond her capacities, drawing her into skills and embedding her in patterns of feeling and doing that she would not otherwise have had access to (Tronick, 2005). These patterns afford a coherence to infant - or indeed adult - experience. They are what we know and can know more through. They serve to invite infants into our culture, but can just as easily be advantageous as negative and disadvantageous. Armed with such coherent 'affective centres of gravity' the infant is repeatedly pulled towards them (Panksepp \& SmithPasqualini, 2005). In new interactions the infant acts - as do adults - in ways which reproduce such exchanges and feelings which at least have the advantage of being familiar and coherent. This induces a corresponding affective ethos even in new partners who sense and respond to whatever 'dis-connecting' messages the infant is offering and inviting.

In sum, infant communication at two months seems to be much more than the detection of contingencies, involving a degree of sensitivity to particular emotional expressions in others, and to the emotional tone of interactions - what Daniel Stern calls 'vitality contours'. These are the rhythms and tempos of ordinary actions, present in everything we do and say, and generally far harder to conceal and disguise than what we normally call emotional expressions. The meaningful perception of emotion in others may, according to Trevarthen, be the key to the evolution of affect. According to him and according to some communicative rather than 'read-out' theories of the evolution of affective expression, emotions evolved because they were meaningfully perceived by others (Fridlund, 1994). There is no point in being able to smile unless there is someone out there to feel its impact. There is no point in being able to express sadness unless someone can perceive and re- spond to it. Whether or not this was the case in evolution, the affective communication of the two-month-old shows not only a sensitivity to the relevance and appropriateness of others' emotional expressions and rhythms, but also a remarkable ability to learn about their meanings from the responses of others to their own emotions. The expression of emotion seems truly reciprocal in the sense that we are constantly expressing emotion in relation to the ongoing responses of others - their meanings changing for us, perhaps throughout life.

\section{Functional features of dialogue and communication: openness and recognition}

Is this the only way in which we can ask whether something really is communication and dialogue? There is something very unsatisfying about using structural criteria to identify a process of affective engagement. There have been innumerable attempts across a variety of disciplines to capture something that, like 'quality', is better experienced rather than reduced. Two aspects of such attempts at identifying what might be called 'functional' features of dialogues are 'openness' and 'mutual recognition'. These are vague concepts and may be better studied as properties of the relation rather than of the individuals involved in it; but the challenge they pose does need to be addressed. Dialogue cannot be scripted and pre-determined. It must possess within it the possibility of going down a road which none of those engaged in it could have known about. When Martin Buber spoke about dialogue he was capturing something of this quality of openness as well as the potential for dramatic change that openness to the unknown allows:

for what I call dialogue, there is essentially necessary the moment of surprise.... The whole charm ....is that I do not know and cannot know what my partner will do. I am surprised by what he does and on this surprise the whole play is based (Kirschenbaum \& Henderson, 1989, p. 57).

And genuine dialogue - where each is really open to the other - involves what many have 
called a 'confirmation' or 'recognition' by the other. In every engagement, according to Hegel, there is the risk of not being 'recognised' by the other in the way one has acted - it is only when we are recognised by another person that we receive confirmation about ourselves. If the engagements in early infancy show features of this openness to and being recognised by the other, this may show us how second-person relations really do work in the lives of infants and adults.

We take the unscripted quality of our conversations for granted, but it is precisely this that keeps us alive in our engagement, whether with the physical world or the social world. When things are open, the unexpected and the novel can happen, and whether rewarding or conflictual, they demand resolution and explanation - making a 'lived story' as Stern puts it. And when such moments are shared, something bigger than either of the participants is released. "The moment when someone can participate in another's lived story, or can create a mutually lived story with them, a different kind of human contact is created" (Stern, 2004).

Does mother-infant interaction show these features? Infants certainly can be surprised by others' acts - this is evident in all of the perturbation studies - showing that infants have at least by two months already built up expectations of what the other person will do, and what the engagement will be like. It is also evident that infants are pretty sensitive to subtle fluctuations in others' moods and expressions, once again revealing their expectations from the relation. Their own acts in the engagement are influenced by the acts they experience from others: in terms of the openness of the infant-adult engagement, there is no doubt that we are dealing here with an open system. To use Ed Tronick's theory of dyadic states of consciousness, it seems that even at two months we are dealing with engagement in which both partners are open to and influenced by the other. Dan Stern's notion of 'now' moments - where this openness results in startling moments of change and shift of gear in the relationship - may be useful to identify just how infant engagements with other people actually develop through emotional sensitivity to the unpredictable (Stern, 2004).
Infants also seem to need the unpredictable and the surprising - the totally predictable is boring. And when they start to dis-engage from adult engagements, even if briefly, adults often introduce intentional perturbations and violations of expectation - creating variations of intensity and action in games and songs and speech - primarily to keep the infants' interest continually engaged. Such intentional violations, however, aren't done by infants until a few months later as we will see when we discuss teasing by infants. But once they start, they take the lead and do it to extents that adults wouldn't do to them! Openness and unpredictability is central to teasing (and more generally, to playfulness) - and infants, are beginning to engage in acts which seem deliberately aimed at surprising other people - they tease and show-off and clown - with intense enjoyment. Confirmation or recognition of the other can happen - or not happen - in many ordinary ways. In all the perturbation experiments the adult (whether the parent under instruction to hold a still face or the experimenter manipulating the video replay) is explicitly not confirming the infant - not acknowledging or recognising the infant's previous acts or the infant herself. Mothers and other adults asked to engage in still-face experiments sometimes report finding them emotionally difficult - this is why: they are being asked to act as if the infant isn't there - to not acknowledge the infant. Blank unresponsiveness may be a harsher 'disconfirmation' of the partner in interaction than explicit challenge or rejection of the other. We do this in everyday life all the time - sometimes accidentally, sometimes deliberately - and often leaving minor damage in our wake whether we know it or not. The perturbation studies show us (and in this they have succeeded in a moral victory) that it matters enormously to infants - even in these early months.

\section{Communicative Intentions: Towards mutuality}

Nonetheless, two month-olds' behaviour is still (at least implicitly) relegated to the category of pseudo-communication. According to a modern 'cognitivist' argument most clearly expressed by Michael Tomasello, infants neither have com- 
municative intentions themselves nor understand communicative intentions in others until they are about 9 months old.

The theory goes like this. To engage in genuine communication (rather than just interaction,) the organism (infant, animal or alien) needs both to have communicative intentions and to understand that the other organism has them. Communicative intentions are not ordinary intentions, for example those which are directed towards things in the world. They are different in that they are directed towards minds and mental (or intentional) states. To be directed towards minds, communicative intentions must involve an 'intentional object' - a thing which is represented in the mind; they must be 'about' something. Shared 'topics' of communication are not evident until the end of the first year, either in terms of the infant referring to them or in terms of the infant understanding the adult's reference to them, and therefore, it is concluded, the two month-old neither has communicative intentions nor understands them in others.

Communicative intentions, in this view, are seen as plans for action that exist in one mind and are directed towards another mind. The body is seen as a tool for conveying the communicative intention, not in itself intentional or expressive. The successful communication, then, is the idea that exists in one mind about the idea that exists in the other mind. It follows from this that until hidden entities can be conceptualised (late in infancy) communicative intentions cannot exist (the infant has no idea of a mind to direct them to) and cannot be understood (the infant has no idea of a mind from which something might be coming). This assumption of the mind-to-mind nature of intentional communication seems fairly firmly founded on a dualism between mind and bodily movements.

From that perspective, the two-month-old's expressions of emotion towards another person, her reciprocal responses to the expressions of others, her seeking of engagement in face-toface contact with other persons and her adjustment to patterns of engagement become an irrelevance to communication. They are bodily reactions to the bodily movements of others; they are not mental actions directed to others or reactions to the mental actions of others. They can be dismissed as bodily and biological because they are not representationally mediated.

Referring to the two-month-old's reported inability to perceive others' perceptions of the outside world, Tomasello argues "When the infant did not understand that others perceive and relate to an outside world there could be no question of how they perceived and related to $m e "$. The grasp of a mental object is seen as a necessary pre-requisite for understanding that others want to communicate "for understanding that someone else wants me to attend to $\mathrm{X}$, that is, for understanding a communicative intention" (Tomasello, 1999). Tomasello is reflecting a generally held belief that there must be a separate object in mind which is shared by both partners for the sharing to be called genuinely communicative (if we are talking about communication) or for it to be called genuinely joint attentional (if we are talking about attention) or genuinely joint intentional (if we are talking about intention). In other words, the crucial assumption is that acts between people must be mediated by representations of something else if they are to be genuinely mental. This implies that for me to genuinely communicate with you I need an intermediary - an idea, an object, an instruction, some other entity which you and I can share. There is, in this view, no direct relation possible in Buber's terms of an I-Thou relation. Or at least, it does not constitute mental relation, only bodily. The insistence on an 'object' for communication, then, is also the result of a continuing, if unintended, commitment to a mind-body dualism.

Such an approach to communication adopts a traditional 'telegraph' metaphor, in which you need a sender, a receiver, a common code and a message. Just as in telegraphy, everything is believed to happen in a nice tidy sequence with each act of communication involving a clear sender and a clear receiver and a clear prior intention and message. But neither in infants nor in adults is there such a sequentiality and individuality to communicative intentions, nor are communicative intentions preformed and in existence prior to the communication itself. Although we can and sometimes do talk to each other in this way - planning to say something, 
conveying the message and waiting for a response - communication is often far more chaotic and synchronous. Many writers, John Shotter and Alan Fogel to name two, argue persuasively that meanings, intentions and communicative intentions change and unfold within the process of interaction and therefore it makes no sense to look for communicative intentions and meanings as things independent of interaction (Shotter, 1998). In what he calls a 'continuous process model' Alan Fogel argues that communication can imply "a negotiated and dynamic process in which whatever is shared is created through the process of co-regulation: not known by one person in advance and communicated as a message to the other" (Fogel, 1993, p. 3).

\section{The paradox of communication}

There is a strange paradox about communication. Language is often seen as the tool which opens the door to private mental experience. The use of language in dialogue can make private experience public. We speak of dumb animals and speechless infants and say that if only they could talk, we would know what they think and feel. Communication is seen as leading to the sharing of minds. This makes a lot of sense, at least in our highly verbal culture.

However, how does the infant acquire the means to use language to share mental experience? In order to use language, we must already know what is meant by it, and indeed that something is meant. Before a word can be shared, its meaning must already be shared in order to know what the word stands for, and people have to be understood as having minds with meanings. In other words, in order to communicate, we must already understand that others understand and what they understand.

Put this way we have a paradox. Communication is necessary to know about minds, but communication implies that we already know about minds. How do we resolve this? Paradoxes are frustrating things. But this one may be more apparent than real. It emerges from assuming that the communication of meanings is a representational act. That is, that the content of a communication (represented in the mind) has to precede communication itself.

Ludwig Wittgenstein showed that if you assume that representation precedes communication, you cannot explain communication at all. You have no way of explaining how the shared meanings originated in the first place. A meaning must be public - or shared - in order for it to be used in conversation or communication. The apparent paradox we have been considering then is simply a function of putting the metaphysical cart before the horse, by assuming that mind and the contents of mind (meanings) are private before they become public. If we accept Wittgenstein's solution the question becomes: what meanings does the infant share with adults? When and how do these meanings emerge? If communication is taken as primary (i.e., if we accept the 'hermeneutic circle' in this question) the paradox disappears. Words, and gestures, can only achieve their meaning if they are grounded already in shared agreement about what they mean or refer to. They have to be grounded in shared meaning before they ever emerge as separable and represent-able meanings. But they cannot do this in the absence of engagement. Thus, communication both sets the ground for, and reflects, mind knowledge.

"Nothing will come of nothing: speak again" said King Lear to his favourite daughter (King Lear, Act 1, Scene 1). Communicative intentions cannot emerge out of their total absence. They develop, but from a ground which is simpler, the further back you go in developmental time. Intentional communication is evident from early infancy. Its development is primarily in its referents, its informational content and its scope. The processes of intentional communication become more complex over time, but they do not emerge, belatedly, as a result of inferences about others' mentality after many months of pseudo-communication. They must be already be present in the early communicative engagements of the two-month-old.

\section{Summary}

So, is the communication of the two monthold intersubjective? Does it show the infant's 
awareness of the other as a person, a psychological being? All depends of course, on what we mean by a person and a psychological being. The structural and functional features of dialogue and communication explored here can throw light on questions concerning the infant's awareness of the other. Dismissals of the 'conversations' and complex interactional sensitivities of the two-month-old as pseudo-communication or mere contingency detection reveal dualist assumptions about the (im)possibility of interpersonal understanding without representation. The two month old seems to both invite and reveal a recognition of the psychological qualities of people.

\section{References}

Adamson, L. B. (1995). Communication development during infancy. Boulder, Colorado: Westview Press.

Adamson, L. B. \& Fric, J. E. (2003). The still-face. A history of a shared experimental paradigm. Infancy, 4, 451-473.

Cohn, J. F., \& Tronick, E. Z. (1983). Three-month-old infants' reaction to simulated maternal depression. Child Development, 54, 185-193.

Collis, G. M., \& Schaffer, H. R. (1975). Synchronisation of visual attention in mother-infant pairs. Journal of Child Psychology and Psychiatry, 16(4), 315-320.

Dewey, J. (1925). Experience and Nature: The Paul Carus Lectures (p. 135). Peru, Illionois: Open Court Publishing.

Dondi, M., Simion, F. \& Caltran., G. (1999). Can newborns discriminate between their own cry and the cry of another newborn infant? Developmental Psychology, 2, 418-426.

Field, T. M., Woodson, R. W., Greenberg, R., \& Cohen, C. (1982). Discrimination and imitation of facial expressions by neonates. Science, 218, 179-181.

Fogel, A. (1993). Developing through relationships: origins of communication, self and culture (p.19). Chicago, IL: University of Chicago Press.

Fridlund, A. (1994). Human facial expression: An evolutionary view. San Diego, CA: Academic Press.
Gergely, G. (2003). The development of understanding of self and agency. In U. Goswami (Ed.), Blackwell's Handbook of Childhood Cognitive Development (pp. 26-46). Malden, MA: Blackwell.

Gergely, G. (2004). The role of contingency detection in early affect-regulative interactions. Social Development, 13, 468-488.

Gergely, G., \& Watson, J. (1996). Early socio-emotional development: contingency perception and the social bio-feedback model. In P. Rochat (Ed.), Early Social Cognition:Understanding others in the first months of life (pp. 101-136). Mahwah, NJ: Erlbaum.

Gianino, A., \& Tronick, E. Z. (1988). The mutual regulation model: The infant's self and interactive regulation coping and defense. In T. Field, P. McCabe, \& N. Schneiderman (Eds.), Stress and coping (pp. 47-68). Hillsdale, NJ: Erlbaum.

Hamilton, M. S. (1990). Maternal depressive affect: its effect on infant affective regulation. Dissertation Abstracts International, 50(9-B), 3919.

Hatzinikolaou, K. (2002). The development of empathy and sympathy in the first year. PhD thesis, University of Reading, U.K.

Haviland, J. M., \& Lelwica, M. (1987). The induced affect response: 10 -week-old infants' responses to three emotion expressions. Developmental Psychology, 23(1), 97-104.

Izard, C. \& Malatesta, C. Z. (1987). Perspectives on emotional development 1: Differential emotions theory of early emotional development. In J. Osofsky (Ed.), Handbook of Infant Development (pp. 494-554). Chichester: John Wiley.

Kaye, K. (1982). The mental and social life of babies. London: Methuen.

Kirschenbaum, H., \& Henderson, V. L. (Eds.). (1989). Carl Rogers: Dialogues. (Chapter 3, p. 57). Boston, MA: Houghton, Mifflin.

Legerstee, M., \& Varghese, J. (2001). The role of maternal affect mirroring on social expectancies in three-month-old infants. Child Development, 72(5), 1301-1313.

Lindy, B., \& Field, T. (1996). Newborns of mothers with depressive symptoms are less expressive. Infant Behaviour and Development, 19, 419-424.

Markova, G., \& Legerstee, M. (2006). Contingency, imitation and affect sharing: Foundations of in- 
fants' social awareness. Developmental Psychology, 42(1), 132-141.

Markova, I. (1982). Paradigms, Thought and Language. Chichester: John Wiley.

Murray, L. (1980). PhD Thesis; Murray, L. \& Trevarthen, C. (1985). Emotional regulation of interactions between two-month-olds and their mothers. In T. Field \& N. Fox (Eds.), Social perception in infants (pp. 101-125). Norwood, NJ: Ablex.

Nadel, J., Carchon, I., Kervella, C., Marcelli, D., \& Reserbat-Plantey, D. (1999). Expectancies for social contingency in 2-month-olds. Developmental Science, 2(2), 164-173.

Nelson, C. A., \& Horowitz, F. D. (1983). The perception of facial expressions and stimulus motion by two- and five-month-old infants using holographic stimuli. Child Development, 54, 868-877.

Panksepp, J. \& Smith-Pasqualini, M. (2005). The search for the fundamental brain/mind sources of affective experience. In J. Nadel \& D. Muir (Eds.), Emotional Development: Recent Research Advances (pp.5-30). New York: Oxford University Press.

Selby, J. M. \& Bradley, B. S. (2003). Infants in groups: A paradigm for the study of early social experience. Human Development, 46, 197-221.

Shakespeare, W. King Lear, Act1, Scene 1.

Shotter, J. (1998). Agency and identity: A relational approach. In A. Campbell \& S. Muncer (Eds.), The social child (pp. 271-291). Hove, England: Psychology Press.

Stern, D. (2004). The present moment in psychotherapy and everyday life. New York: W. W. Norton \& Co.
Tomasello, M. (1999). Having intentions, understanding intentions, and understanding communicative intentions. In P. D. Zelazo, A. W. Astington \& D. R. Olson (Eds.), Developing theories of intention (pp. 63-75). Mahwah, NJ: Lawrence Erlbaum Associates.

Trevarthen, C. (1977). Descriptive analyses of infant communication behavior. In H. R. Schaffer (Ed.), Studies in mother-infant interaction: The Loch Lomond symposium (pp. 227-270). London: Academic Press.

Trevarthen, C. (1998). The concept and foundations of intersubjectivity. In S. Braten (Ed.), Intersubjective communication and emotion in early ontogeny (pp. 15-46). Cambridge: Cambridge University Press.

Tronick, E. (1989). Emotions and emotional communication in infants. American Psychologist, 44(2), 112-119.

Tronick, E. Z. (2003). Things still to be done on the still-face effect. Infancy, 4(4), 475-482.

Tronick, E. (2005) Why is connection with others so critical? The formation of dyadic states of consciousness and the expansion of individuals' states of consciousness: coherence governed selection and the co-creation of meaning out of messy meaning making. In J. Nadel \& D. Muir (Eds.), Emotional Development (pp. 293-316). Oxford: OUP.

Tronick, E., Als, H., Adamson, L., Wise, S., \& Brazelton, T. B. (1978). The infant's response to entrapment between contradictory messages in face-toface interaction. Journal of the American Academy of Child Psychiatry, 17, 1-13. 